\title{
What Am I Getting Myself Into?
}

\author{
William F. Cornell
}

\begin{abstract}
This article weaves together a description of the process of transactional analysis psychotherapy with an account of one client's therapy - a client who asked, "What am I getting myself into?" as she started her work. This essay seeks to convey both the mechanisms and the experience of psychotherapy. It emphasizes work with psychological scripts and transference, the exploration of new possibilities for thinking and living, skill development, and the promotion of new neural pathways as the primary means of change in psychotherapy.
\end{abstract}

"So, what am I getting myself into here?"

Suzanne asked me this question toward the end of our initial session. She had led quite a life up to the point she decided to enter therapy. As she approached retirement from her post as a university professor and campus minister, her life, at least from the outside, seemed full of accomplishment and-one would imagine-personal satisfaction. Suzanne was one of a handful of women to gain admission to a certain theological seminary and eventually to become ordained, although only after a valiant struggle. Ultimately, she rose to a position of leadership within her denomination.

Suzanne was the only one of her siblings to leave the area where she grew up, the only one to go to college, the only one to win any visible acclaim. And yet she was the black sheep of the family. Now, as she approached retirement, she was alienated from her family and did not experience much pride or satisfaction in her professional accomplishments. Throughout a lifetime of professional struggle and gain, she lived alone, could not sustain close personal relationships, and suffered recurrent bouts of depression. She was terrified of a retirement marked by loneliness and depression. Suzanne decided to enter psychotherapy to see if she could understand and change her depressive and isolating tendencies and thus anticipate a different sort of retirement. Suzanne, like many people who enter psychotherapy, was extremely successful in some realms of her life and lost and ineffective in others. Psychotherapy works to deepen selfunderstanding so as to increase the range of personal autonomy and effectiveness in a person's life.

She consciously chose transactional analysis psychotherapy because she had read a number of transactional analysis books and found them sensible and somewhat helpful. She had done enough reading and talking with colleagues to know that many of transactional analysis authors and organizational leaders were women. Some had even made contributions to the feminist literature. She said she understood herself better from the reading but still could not significantly change her way of living. She chose me as her therapist because she knew I practiced transactional analysis and because she knew a couple of colleagues who had seen me for treatment. They considered their work with me successful and had recommended me to her.

After Suzanne asked what she was getting into, I responded that I did not really understand the intent of her question. She explained that she wanted to know what she could expect to accomplish and how psychotherapy might help. She wanted to be reasonably sure that she was spending her limited time and money well. She said she knew people who had really changed in 
psychotherapy, "but I don't understand what psychotherapy is or how it works." The answer did not roll out of my brain and off my tongue. I took up her question seriously and answered it as best I could. At that point in my practice, I routinely asked my clients what they needed to know about me, but it had never occurred to me that clients might have the same question about psychotherapy itself. How does it work? What am I getting myself into? I have since learned that many clients enter therapy with this question in mind but do not feel free to ask it.

This article is my answer to the questions of how transactional analysis therapy works and what you, as a client, might be getting yourself into. Your therapist-even if she or he has a transactional analysis frame of reference-may have a different perspective. Ask. Push past the standard theoretical explanations to talk more openly with your therapist about what you each know and expect of psychotherapy, what you each know and believe about how people change. That initial discussion can lay an important foundation for the work you will do together.

Psychotherapy is a hard and exciting endeavor. It is work, rewarding work. Transactional analysis psychotherapy is a collaborative effort ("collaborate" comes from the Latin word collaborare, which means "labor together"). You and your therapist will have a working relationship, one that may be gentle and supportive at times but challenging, conflictual, and even disorganizing at others. Your therapist's primary job is to provide you with a respectful and reliable space within which the two of you (or perhaps a group of you) can reflect, explore, and experiment with feelings, beliefs, and interpersonal behavior. Things that you may have taken for granted about yourself, life, and others will be opened to question. You will have the opportunity to examine how you relate to yourself internally and with others interpersonally. You will work with your present-day relationships, on the one hand, and look at the lingering influences of childhood relationships on the formation of your beliefs, feelings, and behavior, on the other. Your willingness to question, be questioned, reflect, challenge your beliefs, and experiment with new possibilities is at the heart of your job as a client.

In the rest of this article I will consider how transactional analysis psychotherapy works by addressing four areas of the therapeutic process: script formation and insight, new possibilities for feeling and thinking, skill development, and changes in neural pathways. I will return to Suzanne's life and the work she and I did together to offer some concrete examples of how the process works.

Why I Was Drawn to Transactional Analysis

Transactional analysis was created during the 1950s and 60s by Eric Berne, a psychoanalyst who wanted to develop of model of psychotherapy that was more humanistic and user-friendly than the psychoanalytic model in which he had trained. He wrote several important books about psychotherapy for psychotherapists. He also wrote Games People Play (1964), which became a huge best seller and a model for the many self-help books that have been published since. Berne developed terms - games, rackets, scripts, and strokes - that he hoped clients would find practical, easy to grasp, and a bit humorous. In fact, much of the early terminology of transactional analysis has by now become part of our ordinary language.

Berne called his model transactional analysis to distinguish it from psychoanalysis and to emphasize that this new approach looked actively at the meaning of what goes on between people as well as what goes on within our own minds. In fact, in transactional analysis we look at both transactions (interactions) between people and transactions with ourselves, within our own minds. Berne recognized that we all have states of mind within ourselves, which he called ego states. These can be quite varied and even contradictory because they are formed at different ages and within the context of different relationships. Berne studied the transactional dynamics between people and within groups, but he also recognized that often the most compelling and 
challenging interactions are the ones we have within ourselves! Therefore, Berne taught therapists to pay attention to the conversations people have with others and the conversations that they have with themselves.

I was drawn to transactional analysis more than 30 years ago for two reasons. As a psychology undergraduate student, I read a paper by Berne in which he described leading supervision groups in a clinic where the clients who were being discussed by their therapists were invited to attend the consultation group. Both therapist and client thus had the opportunity to discuss what was working and what was not, to examine their patterns of transactions, and to look together at ways to improve their work. I was enormously impressed by the act of respect that Berne extended to clients in this learning structure. He presumed that whatever the difficulties a client was struggling with, he or she wanted to get well and would become seriously engaged in the therapeutic process.

Transactional analysis also offered an approach that supported both cognitive/behavioral interventions and affective/psychodynamic work, in contrast to most models of psychotherapy, which choose one side or the other of that therapeutic divide. The dual focus in transactional analysis offers an important flexibility to clients in terms of the models of therapy that can be used.

For example, there is tremendous pressure these days from insurance companies and health delivery systems for short-term counseling and psychotherapy, which almost always takes the form of some version of a cognitive/behavioral therapy. For many people entering treatment that uses a cognitive/behavioral model, the question is, "Please help me understand what I'm doing and how to do this more effectively." For a number of therapeutic issues, this level of intervention is sufficient. And for many people, it is a familiar way of seeking help. You may have conversations like this with trusted friends, family members, or a minister, colleague or teacher who might respond, "Hey, this is how I think about that. Try it this way. This works for me, maybe it'll work for you."

Of course, friends, family members, ministers, and others may have some investment in your making a particular choice. One of the advantages of seeing a therapist is the offer of more objectivity. A therapist will help you look at how you think and how those thoughts influence your behavior. A therapist will not (unless you are in emergency circumstances) tell you what to think or do. Sometimes a cognitive/behavioral level of intervention relieves symptoms for a while, but usually the quality of a person's life and his or her emotional/psychological structures do not change significantly. People realize there is more that needs to be done, that a different level of self-assessment is needed. This points to longer-term psychotherapy. Here transactional analysis offers a strong advantage for clients who decide to make this shift in focus: They do not need to change the therapeutic model or therapist to deepen and extend their therapy.

Getting back to Suzanne, at the time she entered therapy with me, she knew she would be in longer term, psychodynamic therapy. That was what her question, "What am I getting myself into?" was about. The nature of long-term psychotherapy is more of a mystery to many people. It is not a normal and familiar way of relating to someone else. Images of "shrinks," "mind readers," and gurus often come to mind. Perhaps the following sections of this article will begin to help you understand how the experience and process of long-term transactional analysis therapy works.

Script, Ruts, and Transference

It is part of human nature to try to make sense of life, of others, and of ourselves. We constantly create and tell stories: We listen to them, read them, watch them on television and in 
the movies. Stories can excite, soothe, disturb, explain, or entertain, thus serving many important psychological and emotional functions. We all have favorite stories from and about childhood; we grow up with family stories and have our own recollections of important childhood events. Stories help us make sense of life, providing not only a chronicle of history but tales of meaning and emotion as well. Life stories can be lived like a historical novel, a great adventure, a fairy tale, science fiction, a romance, a whodunit, a thriller, a tragedy, or even as a bad joke. In Eric Berne's words, we have an innate hunger for structure, by which he means familiar and predictable ways of making sense of ourselves internally and of life outside of us. This need for psychological structure fosters a tendency to create accounts of our lives, or stories, that can provide psychological stability but can also limit how we see the possibilities of ourselves and others. The power of childhood stories can be such that we turn a new experience into the same old thing, not even seeing the new experience. The power of "the same old thing" can create patterns that can make the outcomes of life seem inevitable and change seem impossible.

For example, seen from the outside, Suzanne was typically praised as intelligent, independent, and highly principled. As her therapist, I would not quarrel with these characterizations. At the same time, however, I knew that the story of Suzanne's life, as she experienced it, was considerably more complicated. Remember, she saw herself as the black sheep of the family, the misfit, the unwanted daughter and sibling. She was the youngest (and unexpected) child, a burden to her mother who was turned over to the care of her older siblings. Little Suzanne's sisters and brother were already adolescents, and they did not welcome a new baby. They did not want to be bothered with serving as babysitters or substitute parents. Suzanne gradually came to conclude that depending on anyone was bad news, that being a girl left a lot to be desired, and that she simply did not fit in among others.

Suzanne did not leave home because she wanted to but because she was not wanted. Remember, her siblings all stayed in the area and remained involved in each other's lives and families. For Suzanne, leaving home for college was more of a failure (a banishment) than a success. No one from her family came to visit. In fact, they found her whole life at an urban college threatening.

As a girl, Suzanne had found church comforting, the privacy of prayer and religious fantasy soothing. She found some kindness from the parish minister; she identified with him and eventually set off for a theological college in a major city. However, there she found herself ripped from her family and the comfort of a small country parish. She landed in an academic community that feared women and was dominated by arrogant men. These were not the gentle, sensible parish ministers with whom she had grown up. She found herself, again, a black sheep. Given Suzanne's experience of life to this point, being a black sheep yet again seemed to her to be inevitable and somehow deserved.

Transactional analysis therapists often refer to such stories about oneself and the world as "life scripts." Berne used the term script, rather than story, because it captured the sense that we often feel as though these stories have been written for us within our families and then imposed on us. Although we, in part, create these stories (often unconsciously) ourselves, we may feel as though we are following someone else's wishes, speaking lines handed to us as in a script. As children, we create scripts that seek to adapt to our families and cultures so as to have a sense of belonging and to avoid disapproval. As transactional analysis therapists, we often speak of childhood "script decisions," which can make it seem as though Suzanne (or you) sat down as a child and decided, "So this is what my life is about." It does not happen quite that way. It is more like gradually but repeatedly feeling as though our life and family are teaching us certain inevitable lessons about who we are and what life is going to be like. Some parts of our 
personal stories can be exciting, unpredictable, and open-ended. But the script aspects of the life story feel like the ruts in a well-worn road.

Most of us experience a contradiction between areas of life in which we feel reasonably autonomous and effective and other areas where we feel trapped and ineffective, leading a life that is not really of our own choosing. Are we the author of a story or a character in someone else's design for us? One of the important ways that transactional analysis therapy works is that therapist and client work together to identify the enduring stories of one's life, that is, to identify the recurrent patterns of life script. This is the process of pattern recognition and the development of insight - the capacity to see inside yourself from an outside perspective. Your therapist may never use the word "script," but he or she will help you notice the patterns in your life that seem inevitable, those things that you keep doing even though you know they do not work.

Scripts often emerge during the therapeutic process and are lived out with the therapist. In the transactional analysis language of Eric Berne, this living out of script is called a "game." If you read about psychotherapy these days, this phenomenon is usually called transference. For example, Suzanne, as the designated black sheep of her family, was extremely sensitive to any signs of my not liking her or "wanting to be rid of her." She anticipated from the beginning (even before meeting me) that as a psychotherapist I would be biased against her religious orientation, regarding it as childish or dumb. Suzanne expected me to want to get rid of her. If I forgot something from a previous session, she viewed this as evidence that "as soon as I'm out of sight, I'm out of your mind." Our work together almost collapsed when I double-booked her session after a vacation. Even though I owned the mistake as mine and the other client agreed to come back at another time, Suzanne felt that I had humiliated her and that this was clear evidence that I did not care and wanted to be rid of her. In Suzanne's mind it seemed perfectly obvious that she had somehow become a bore or a burden to me. It seemed better to leave than be angry with me.

This mistake on my part and Suzanne's reaction to it became a pivotal moment in her therapy. It was clear to her that we were both extremely uncomfortable in the face of my error, but I did not get rid of her. She could see that I could tolerate my own discomfort and maintain an investment in her well-being. This provided her with an emotional space within which we could examine all of her various reactions. She was able to begin to see that the only way she could understand my mistake was as a desire to be rid of her, that this habitual explanation was an expression of her script that imposed a particular meaning on what had happened. If this meaning were accurate, it made sense that she (as usual) should prepare to leave yet another important place of hope in her life and yet again to go it alone.

As she was able to see the power of her script expectations - those well-worn psychological ruts - with me, Suzanne was increasingly able to gain insight into herself. She began standing apart from the power of the stories of her past and saw how these assumptions played out in other relationships as well. She realized that there were other times when she presumed she had become undesirable or a burden to someone and left the relationship. She began to see that there could be other reasons for difficulties in relationships and that solutions could be found to allow her to stay rather than leave.

This story of Suzanne's transference reactions to me underscores one of the most important jobs of the psychotherapist and a crucial piece of how psychotherapy works through the transference. In this instance, her transference reaction (or psychological game) reflected her early childhood experience and decision that she was unwanted. When transference is not examined and understood, it has the power to reduce a new relationship into the same old and predictable story. The analysis of transference is an invaluable means of insight and pattern recognition, a 
crucial mechanism in how psychotherapy works. Often in work relationships, friendships, and intimacy, we live out elements of our script stories without ever being aware of them, feeling instead resigned to predictable ways of relating, inevitable disappointments, and little that seems new or creative. Therapy allows us to engage in a mutual, respectful scrutiny of how and why we do what we do. Part of the therapist's job-a skill that requires a great deal of training and practice - is to stand simultaneously inside and outside this working relationship. The therapist provides a space in which to reflect together and experiment with new meanings and possible ways of relating.

When Suzanne first asked me what she was getting into, part of my reply was along these lines: "We'll be working actively with what emerges between us as our relationship develops. Either of us, at any time, can address our relationship directly-conflicts, appreciations, surprises, mistakes, deceptions, impatience, excitement, misunderstandings - whatever may affect the quality and effectiveness of our relationship. People tend to create in the therapy whatever they tend to exclude or distort in daily life. We need to identify, understand, and change those patterns. It's not always comfortable to do this, but this is a place to practice."

Insight is another essential element in how psychotherapy works. The development of insight is a learned skill. Like most learning, insight requires a teacher and practice. With practice, insight fosters a mind that becomes stronger and more flexible, just as exercise can foster a body that is both stronger and more flexible. It is not always a pleasant process to undertake this kind of self-examination and to see the traps we set for ourselves. Such insight can be very difficult to accomplish without the eyes, ears, and mind of another, which are an important part of what a therapist supplies. Often when a client begins to examine the well-worn tracks of script there can be a deep sense of failure, depression, hopelessness, or shame. The therapist needs to sustain an attitude of curiosity and respect, which will help to make the experience of insight more palatable. Stories, when they are not script bound, often express our wishes, desires, strengths, and creativity. The curiosity, respect, and insight afforded in psychotherapy can go a long way toward restoring the vitality of our life stories and overcoming the deadness of life scripts.

\section{New Possibilities}

Suzanne reported to me in her first session that she had gained insight by reading transactional analysis books, but she could not yet turn the insight into action. Insight, in and of itself, does not necessarily lead to change. However, new possibilities emerge within the therapeutic process through insight ("I never thought of it that way before"), emotions that emerge in therapy ("I didn't know these feelings could be acceptable to someone"), and the therapeutic relationship ("I don't know what to expect of you").

Insight is primarily a cognitive process. It is a necessary, though often not sufficient, condition for change. Suzanne's experience of gaining insight through reading but being unable to actualize her insights is not uncommon. For example, she was afraid to retire and afraid not to retire. Her wishes for a life with less depression and more intimacy were accompanied by fear, anger, and shame. As an adult, she was able to channel her anger into professional causes: the rights of women in her church, the responsibility of the church to the disadvantaged, the role of academic and religious freedom in campus life. There her anger accomplished a great deal. But she could not bring her anger to bear on the loneliness of her personal life: to solve problems with friends rather than leave them, to make effective demands on those she wanted more from, to move toward people she desired. In her personal relationships her anger took her away from people, not toward them. Even in sessions with me, revealing her desire to be closer to friends felt frightening and shameful. All that she could imagine was that she would be exposing herself to the disinterest of others and thus to further rejection and humiliation. The depression 
created by her loneliness seemed preferable to the humiliation of rejection. She could be alone and understand herself better through her reading, but she could not be alone and figure out how to change herself.

Over the course of therapy, clients typically find themselves returning to childhood experiences as they explore new possibilities in the present. Suzanne needed to look back at her familiar memories and stories of childhood, to view them now with an adult's mind rather than only through a child's eyes. Through a child's eye, she was an unloved and unlovable burden. The life she saw around her was hard on everyone. She hated being the cast-away child but dreaded becoming an adult. She admired her father for his hard work and pride, but she rarely saw him happy. Her mother seemed happier, but Suzanne saw her as self-indulgent and irresponsible, felt disgusted by her, and hated herself for hating her mother. She was consumed with envy and jealousy toward her siblings. As a young girl, she was convinced that her family somehow knew she had these horrible feelings, so they made her the black sheep. As an adult, she felt as a Christian she should rise above these feelings. In her heart Suzanne felt sinful and filled with shame. Her feelings, perhaps, could be forgiven, but they did not deserve interest or compassion.

In therapy, Suzanne found space for all of her feelings. She began to understand how her anger and hatred were a defense against her loving feelings and the helplessness she felt to make a place for herself in her family. She began to feel that therapy was a place for her. It often surprised her that I did not render judgment about her hatred and jealousy, that I did not reassure her that her family really did desire her or had done the best they could. Instead, I remained steadfast that she could create a different environment for herself. Perhaps the biggest surprise was that when something went wrong between us we mostly managed to learn something from it. We did not distance from one another. Gradually she could understand and then feel that bad feelings were indications of desires that remained unacknowledged and of problems that needed to be solved.

Transactional analysis therapists often make use of contracts - clearly stated, mutually negotiated therapeutic goals - to explore new possibilities for behavioral and emotional change. New experiences, however much desired, can be enormously threatening. Letting go of a familiar emotional or relational way of being (Berne's structure hunger) is a complex and often anxiety-provoking undertaking. The end result of something new is something unpredictable. Therapeutic contracts are a means of managing the rate of experimentation, the size of the risk, and the degree of anxiety involved in trying something new. Gradually new experiences accumulate to buffer the old, familiar pains and failures and create the ground for new, more vigorous stories. We gradually internalize new models for ourselves and about how relationships can work.

\section{Skill Development}

When we are reasonably fortunate, childhood and adolescence are years of tremendous learning and skill development. A satisfying life is a skilled life, the product of a lot of learning. We need skills at forming and keeping social/loving bonds, skills for separation and differentiation, skills for healthy aggression and conflict resolution, skills for work, skills for play, skills to think and create meaning in life, and skills to deal with frustration, failure, and personal misdeeds. Most of us are fortunate enough in our family and school environments to arrive at adulthood with a reasonable range of skills. And most of us have significant gaps or downright gaping holes. Most of us try to rely on our familiar skills to cover or compensate for the gaps.

But it is the gap that brings most people into psychotherapy, which is a rich means to mind and mend the gaps in our range of skills. Part of the reason it helps is that skill development 
requires opportunities and practice.

Far more often than not, people come into psychotherapy with a deeply held belief that there is something wrong with them (or with someone else). An important part of the assessment that a therapist undertakes is to evaluate developmental gaps and skill acquisition. Clients are often plagued by self-perceptions of character flaws, sinfulness, stupidity, failure, shame, or unlovableness (or the projection and blame of such qualities onto others), all of which intensify feelings of hopelessness and helplessness. It is a powerful therapeutic experience to have a therapist translate self-blame or projective blaming into areas of needed skills.

To return again to Suzanne, if you compare the list of developmental skills listed at the start of this section with the skills evidenced in her family as Suzanne was growing up, the gaps are glaring. Suzanne could not learn what was absent in the environment, could not learn what the people around her did not know how to do (or in her eyes as a child did not want to do for her). One of my jobs as Suzanne's therapist was to help her see the limits of her childhood environment as often just that: limits in the people who were raising her rather than judgments about or reactions to her worth and lovability. She had indeed used the available family skills of separation and hard work to strong advantage in her life. But she knew little of how to give love, receive love, sustain emotional relationships, play, or express feelings and desires in ways that helped those around her know her better. To understand the limited skills in her family (and their limited quality of life) provided Suzanne with a very different and more compassionate perspective on herself and her family. This allowed a gradual reconciliation with her siblings. It allowed her to feel far less flawed and ashamed because she knew she could learn, even as hurt and unsure of herself as she was in the world of relationships.

At times, usually when scared or disappointed, Suzanne would become angry at how "unreal" therapy was, attacking it as "a weird kind of bubble that has nothing to do with real life." "Maybe," she would say derisively, "if everyone at the university were in psychotherapy, then this would all seem more real." This was one of Suzanne's ways to "leave the scene," to escape the uncertainty or vulnerability of being more engaged with me. Part of my job was to speak to the realities of her uncertainty and her vulnerability while gently persisting in (and if need be insisting on) the exploration of new skills in her life outside the therapy room. She began to discover that some of the people around her had a far greater range of skills in life than her family members had. She began to realize that a few people would welcome her tentative (and sometimes awkward) efforts at trying new skills. It is not easy, for example, to give up sarcasm and say "I'm scared." But she found a few people in her daily life who actually seemed to prefer a rather scared and tentative Suzanne to a distant and sarcastic one, even in an academic environment!

The initial opportunities for skill development typically occur in the therapy office with a therapist and/or a therapy group. But a therapist and treatment group can only provide so much. Then it is the job of the client to carry the work with the new skills outside of the therapeutic setting into daily life. Usually there is a period of time when you may carry your therapist around in your mind ("in your hip pocket," Berne used to say). When a colleague of mine, who had been in therapy with Eric Berne, read the first draft of this article, she wrote to me about an experience with Berne:

When I was a kid, I was prettier than my older sister. When anyone complemented me, my mother would whisper to them, "Please, stop it," as it would hurt my sister's feelings. Needless to say, I felt guilty about being attractive. When I was in therapy with Berne, I was overweight, bought no new clothes, and so on. One day he told me, "You should fix yourself up." He pulled out his prescription pad and wrote on it, "License to be beautiful." I carried that prescription around in my wallet for years. That was 35 years ago, and I know I 
still have that piece of paper somewhere. Soon after that I lost weight, learned how to use makeup, bought new clothes, and VIOLA!

For a period of time, what is new seems possible only because of the therapist. The emerging possibilities seem to belong more to the therapist than the client, in a kind of psychological dependency. This dependency (the hip-pocket cure) is changed only when the client practices these new skills in his or her everyday world. Learning gradually becomes internalized as belonging to the client, not a product of the therapist. Just as the power of the disappointments of childhood need to be broken for insight to occur, so too must the power of attribution to the therapist be broken for learning to be internalized.

\section{Changes in Neural Pathways}

These days advertisements and the popular press suggest a pandemic of mood and mental disorders - depression, anxiety, social anxiety, obsessive-compulsive disorder, attention deficit disorder, bipolar disorder-affecting adults and children alike. Medication is all too often suggested as the magic solution. Although medication can sometimes enhance the effectiveness of psychotherapy and at other times is a necessary component of psychotherapy, it is rarely sufficient to achieve lasting change. Many of the life problems that bring people into psychotherapy - loss of a loved one, low self-esteem, confusion about meaning and purpose in life, difficulties in separation and autonomy with loved ones, intimate and sexual dissatisfactions, problems with anger and control-may not be significantly helped by medication and certainly are not cured by a pill.

To appreciate why, it is helpful to understand a little about the workings of the brain. The 1990s were known as the "Decade of the Brain" in recognition of the tremendous strides that new technologies made in the study of that organ. Today our understandings of mental and emotional functioning continue to unfold at a rapid rate. New research has, among other things, facilitated the development of many new drugs as we better understand the structure and neurochemistry of the brain. These are exciting developments, and it is easy to imagine how medication can be helpful to those who seek psychotherapy. After all, while most of us have not taken an antidepressant, almost everyone has taken an aspirin to chase away a headache. In the same way, it is not hard to imagine the effects of medications on the brain. In contrast, it is a bit more difficult to grasp how talking to someone, as in psychotherapy, can also have an effect on our functioning as well.

One of the outcomes of the Decade of the Brain is an understanding of how the brain creates a mind, that is to say, how the experience of the mind is created in the brain. For a long time, it seemed like the mind and its invisible, subjective realms of experience were the territory of philosophers, psychotherapists, and poets. The brain, as an objective, neurochemically based organ of the mind, was the territory of scientific researchers. There was little dialogue, and often great suspicion, between the two fields of study. Contemporary brain research now demonstrates the myriad of links between brain and mind, and the clinical and research disciplines are in ever closer dialogue.

Why is it that medications alone are often not sufficient for many of the issues that bring people into psychotherapy? At the heart of the answer to this question is the fact that most psychotropic drugs do not significantly impact the cerebral cortex, which is a part of the brain crucial to many of the cognitive/emotional difficulties that bring many people into psychotherapy. What is it that the talking work of psychotherapy can accomplish that medication cannot? In a highly readable book, The Talking Cure: The Science Behind Psychotherapy, Vaughn (1997) described the relationship between medication and psychotherapy this way: 
And even though sometimes taking medication and feeling better can help people feel quite different and can allow them to make impressive strides on their own to change themselves and their lives, often such change is either totally terrifying to patients and results in their stopping the medication, or not enough for them to really change their lives. For most people, medication changes how they feel, but psychotherapy is what changes what their lives are like. (p. 140, italics added)

Medication does not create self-reflection and self-understanding. Medications, when properly prescribed, can shift mood and enhance the capacity for thinking. Chronic, unrelenting depression and/or anxiety do not facilitate clear thinking or hope for the future. Medication in such cases can be invaluable. It can make it easier to think and help restore a fuller range of emotions. Psychotherapy provides a setting in which we learn to think with someone and a means through which we can learn to think about our thinking. Psychotherapy, in an important way, shifts the locus of control in the experience of one's life from external events as causal factors to internal awareness and the development of life skills (one of which may be knowing the importance of your medication). There is increasing evidence from brain research that the brain, from the moment of birth, is a profoundly social organ, that is, it grows and changes through relational experiences. Knowing this helps us to understand how the intense emotional and cognitive interchanges of ongoing psychotherapy literally open and alter neural pathways in the brain.

The life situations that can create the lasting disruptions and inhibitions that bring most people into psychotherapy impact the brain in two fundamental areas: the deep, affective regions of the brain (the cortico-limbic pathways) and the cognitive capacities of the cerebral cortex. Most of the new antidepressant and antianxiety medications improve the availability of essential neurotransmitters in the central, limbic regions of the brain, rather like adjusting the neurochemical bathwater that saturates the deep, affective regions of the brain. These are the areas directly affected and disturbed by early childhood loss, trauma, neglect, deprivation, or violent intrusion, although they can also be profoundly disturbed at any time in the course of life when events overwhelm our personal, emotional capacities and our interpersonal world does not respond with adequate structure and relief.

These deep disturbances of affect are carried in the deep limbic structures and right hemisphere of the brain, the regions of the brain that are prelinguistic and precognitive. When these areas are disturbed, we feel disturbed, although we may not know how or why. These regions of the brain profoundly affect our sense of being, but the meaning of these disturbances comes from a different region of the brain: the left hemisphere of the cerebral cortex.

We looked earlier in this article at the human importance of making sense of things, of creating stories and meaning. It is not until the third year of life that these neural circuits in the left hemisphere of the brain - with their capacity for language development and reflective cognition-begin to develop. These circuits are the story-creating, script-forming mechanisms of the brain. Needless to say, for many people the early years of life, before these cognitive circuits develop, have already left their emotional marks. Thus, we have deep, emotionally colored representations of ourselves and the world around us before we have any capacity to make sense of the world in which we live. These primary emotional representations precede our capacities to think and provide the unconscious shape and tone of emotional and relational worlds. The stories we tell ourselves, the scripts we develop, are a later developmental effort to make sense of deep inner feeling states and relational patterns and to gain some sense of mastery over them.

In addressing the question of what psychotherapy can provide that is different and distinct from what medication can offer, it is important to realize that the neural structure of the upper brain network - the portion of the brain that makes sense of things - is not affected directly by 
our current repertoire of psychotropic drugs. Medication primarily affects the deeper regions of the brain, but not so much the cognitive, linguistic areas of the brain. Psychotherapy affects both. Perhaps the most important thing, as we ask the questions of how transactional analysis psychotherapy works, is to understand how psychotherapy works in this upper region of the brain through its careful, persistent examination of thinking patterns and story/script formation.

For example, Suzanne felt in the core of her being that she was unwanted. We might say that soon after birth she came to "know" in the limbic regions of her brain that something was seriously amiss. She felt something wrong within herself. Being unwanted was all that she "knew" of herself. From her earliest months we can imagine that she felt the distance, impatience, neglect, and hostility of her older siblings. She rarely felt the comfort of another person's warm and welcoming body. Being alone was her most deeply held sense of self. We might say that being alone was the place she "knew" best in the limbic regions of her brain. By the time she reached adulthood, Suzanne had accepted her aloneness, often with pride and defiance (script), but she hated and feared her tendency to become depressed.

Suzanne was not depressed when she entered treatment with me. She had tried medication in the past, was troubled by the side effects, and found it accomplished no lasting change. From her script-bound perspective, she saw medication as a "crutch"; from a more objective perspective, she found it insufficient. She had concluded that her depressions were not biologically based but an outcome of her isolation. She was coming into psychotherapy to address her isolation, not her depression. She was not on medication and made it clear from the start that she did not want to use any. In fact, she threatened that if I suggested medication she would presume that I found her too much of a burden and wanted to be rid of her so she would end the treatment. At the start of therapy, I simply accepted and respected her position about medication. Later, as Suzanne gained more insight into her script beliefs and defenses, we were able to return to her position about medication and her threat to terminate (one of many) as an expression of her script and a cover for her fear of relying on anyone, including her therapist. Eventually she could imagine that if I brought up medication it would not be because I was trying to find relief from experiencing her as a burden. As she learned more about her beliefs about relationships and learned to expect more of people around her, she was able to take up a discussion about medication as a responsible expression of concern for her well-being.

\section{Room for More}

Suzanne did not use medication over the course of her therapy with me, so we will never know if it might have facilitated her work. But we worked hard with the left hemisphere, sensemaking, script-forming part of her cerebral cortex. An important emotional relationship developed between the two of us, one that not only tolerated but welcomed a range of deep, and sometimes difficult, emotions. Her feelings enriched and enlivened her thinking. Her thinking helped her explore new possibilities within herself and among others. Through psychotherapy, Suzanne learned to experience and use her mind differently, and I think her brain changed as a result. Her thinking patterns opened up to novel possibilities. Her mood and affects became more fluid and varied. Suzanne's emotional sense of self opened to a richer range of affects. Desire, longing, and excitement became as much a part of her as depression, anger, and blackness. As she developed more skills for intimacy, she began to feel the pleasure of others' company and the pleasure of her company to others. Suzanne attempted reconciliation with her siblings but only one brother was willing to invite her back, rather tentatively, into his life. At the end of treatment, she remained easily bruised, a bit too quick to move into argument (now tempered by a capacity to apologize and reengage), but now able to imagine a retirement rich with possibilities rather than laden with anxiety and loss. 


\section{Conclusion}

By the time most of us reach adulthood, life has come to feel rather fixed and predictable. Thr predictability of life serves both as a comfort and a constraint. Psychotherapy is a means by which we can examine the constraints of our lives, both in terms of how we live within the actual confines of our daily lives and with those emotional and psychological constraints we impose on ourselves. Good psychotherapy creates more room for fuller living within our minds and in our relationships.

William F. Cornell, M.A., practices, teaches, and writes about psychotherapy in Pittsburgh, Pennsylvania, U.S.A. He teaches, trains, consults with, and learns from groups of psychotherapists from various disciplines throughout the world. Coming from an academic background in behavioral psychology and phenomenology, Bill discovered the vitality of

transactional analysis, psychoanalysis, and body-centered psychotherapy and remains fascinated by the therapeutic process after 30 years in practice. Bill can be contacted at bcornell@nauticom.net.

\section{REFERENCES}

Berne, E. (1964). Games people play: The psychology of human relationships. New York: Grove Press.

Vaughan, S. C. (1997). The talking cure: The science behind psychotherapy. New York: Grosset/Putnam. 